\title{
Queer Asian Subjects: Transgressive Sexualities and Heteronormative Meanings
}

\section{EVELYN BLACKWOOD}

and

\section{MARK JOHNSON*}

\begin{abstract}
This special issue of Asian Studies Review explores comparatively the production and transformation of gender and sexual subjectivities across and beyond South and Southeast Asia. More specifically, papers in this special issue disclose the complex intersections of ethnicity, race, class, gender, religion and nationality through which sexual subjectivities are formed and subject positions inhabited within and across these regions. By tracing the transnational movement of people and the circulation of images and ideas, their appropriations and effects, the papers in this volume reveal mutable and multiple sexual subjectivities that are no longer fixed in place, even as state discourses, hegemonic meanings and individual actors work to attach specific meanings to particular bodies. In this special issue we ask, what are the effects of migration, forced and chosen, on forms and formulations of gender and sexuality for people's embodied and discursive entanglements? How do spatial and temporal, as well as religious, economic and political changes alter and foreclose some kinds of intimacies and subjectivities even as they open and enable others? What are the social and cultural processes through which heteronormativity is articulated, enforced, transgressed and challenged?
\end{abstract}

Keywords: queer, Asia, sexuality, heteronormativity, lesbian, gay

\footnotetext{
* This is an Accepted Manuscript of an article published on-line by Taylor \& Francis in Asian Studies Review on 6 December, 2012, and available online: http://www.tandfonline.com/doi/abs/10.1080/10357823.2012.741037
} 


\section{Extending the Corpus of Asian Queer Studies}

This special issue explores comparatively the production and transformation of gender and sexual subjectivities across and beyond South and Southeast Asia. More specifically, papers in this volume disclose the complex intersections of ethnicity, race, class, gender, religion and nationality through which sexual subjectivities are formed and subject positions inhabited within and across these regions. By tracing the transnational movement of people and the circulation of images and ideas, their appropriations and effects, the papers in this volume reveal mutable and multiple sexual subjectivities that are no longer fixed in place, even as state discourses, hegemonic meanings and individual actors work to attach specific meanings to particular bodies. In this special issue we ask, what are the effects of migration, forced and chosen, on forms and formulations of gender and sexuality for people's embodied and discursive entanglements? How do spatial and temporal, as well as religious, economic and political changes alter and foreclose some kinds of intimacies and subjectivities even as they open and enable others? What are the social and cultural processes through which heteronormativity is articulated, enforced, transgressed and challenged?

Recent reviews in both anthropology and Asian studies journals indicate the vibrant state of regional studies of gender and sexual diversity (see, for example, Sinnott, 2010; Boellstorff, 2005; 2007). They also foreground the broader contribution that those studies have made both to the resurgence of a critical regional perspective and to extending and insisting on a culturally situated analysis of bodies, desires and ways of relating. The papers in this volume are further evidence of both a new confidence in studies of gender and sexuality and an important expansion and development in thinking about and investigating queer Asian subjectivities. While we take South and Southeast Asia as our focus, the articles are not presented by region, but organised thematically cross-regionally. Just as importantly, they attend to circulations of people and things not, as is usually anticipated, in flows 
between the North and the South or the "West" and the Rest, but rather in movements within and between Asian countries and their regional neighbours, for instance, the Gulf or East Asia. These articles not only grapple analytically with new and emergent forms of sexual subjectivities, but also bring a more nuanced and critical historical depth to the processes of sexual subject formation.

Not all of the recent work on gender and sexuality in these regions explicitly draws on or engages with a "queer" theoretical perspective or political agenda. Sexuality studies scholars hold divergent views about the salience and appropriateness of "queer" as a descriptive term and analytical category. Certainly most of the people talked about in our contributors' papers do not share a self-ascribed identification with "queer" either as a social category or a political movement. Yet we use the term "queer" in this special issue both because it effectively highlights the possibilities and constraints of different systems of gender/sexuality and because it makes explicit our concern with the relative instabilities inherent in and productive of both normative and transgressive bodies and practices. By describing people as "queer subjects" we neither presuppose publicly expressed dissidence nor ignore significant differences among them. As Gloria Anzaldúa’s (1987) work suggests, a queer perspective is necessarily intersectional insofar as it simultaneously troubles the fixity of the various subject positions people occupy and recognises the bodily consequences of people's habitations and movements between and across those different and sometimes discrepant positions (see also Rahman, 2010).

\section{Querying “Traditionally" Queer Asians}

Notwithstanding the demonstrable growth and impact of queer scholarship in area studies and anthropology, a number of continuing problematics arise that are, at least partly, the unintended consequences of that work. One is that regionally speaking, both South and 
Southeast Asia have become fairly closely associated with a particular type or kind of gender and sexual pluralism, in Peletz's (2009) terms, seen, for example, in studies of hijra and kothis in South Asia and tomboi, kathoey, bakla and waria in Southeast Asia. Scholars have repeatedly demonstrated that these subject positions emerged historically out of specific colonial and post-colonial social processes. They have also debated the various conjunctions between and transformations brought about respectively by shifts in and policing of gender categories by conservative states and by religious and ethnonationalist discourses, and the rise of more sexualised identities conceptualised along homo/hetero lines produced within international lesbian and gay, human rights and health discourses. ${ }^{1}$

The papers in this volume reframe the question of "traditional" genders versus modern sexualities to ask how we account for, on the one hand, the continuing proliferation of transgressive gender identities, homosexualities, and heterosexualities in South and Southeast Asia, and, on the other hand, the strengthening of dominant discourses that have increasingly pathologised and proscribed gender variance and sexual diversity. Our contributors' essays document queer subjects who find themselves situated in, informed by and in some cases struggling to exceed popular and shifting national views of supposedly "traditional" and thereby relatively acceptable forms of gender and sexual transgression. They significantly move forward debates about transformations of gender non-conformity by directing our attention away from exclusive focus on the impact of sexual identity politics to broader cultural economies.

Writing about transformations in Thai sexual meanings and contexts, Megan Sinnott and Dredge Byung'chu Käng respectively demonstrate not just the ever-increasing proliferation, or in Jackson's (2000) terms, “explosion” of Thai categories of eroticised genders, but also and more importantly the shifting grounds on which those categorical distinctions and personal identities are being made. Sinnott suggests, in a similar vein to 
Jackson's discussion of kathoey, that in recent years the conventional tom/dee dyad that marked the landscape of female masculinities and transgressive female sexualities in Thailand is being supplanted, though not entirely replaced, by new, increasingly sexualised or eroticised identity categories. In contrast to the first writings on "global" gay culture, she points out that these new categories are not dependent on the appropriation or discursive incorporation of Western homosexual identity categories or even on increasingly nuanced distinctions of sexual comportment in active or passive terms.

Sinnott demonstrates that new categories emerge as part of a recent and expanding repertoire of consumption and stylistic appropriations of Korean pop cultural icons. These appropriations are, at the same time, closely tied to borrowings from Thai gay men's categories of sexually receptive (Thai: rap, queen) and active (Thai: ruk, king) to produce a multi-layered world of sexual and gendered desires. For a younger generation of variously self- and other-ascribed versions of tom and dee, this proliferation of styles and identities opens up new spaces for self-aware and self-conscious performances of both female bodied masculinities and femininities. Whereas the pairings of kathoey/man and tom/dee as appropriate sexual partners achieved a level of gender normativity that led to societal tolerance (and coding as "traditional"), according to Sinnott, the new sexualised and samegender pairings, which were previously unthinkable, are more transgressive because they reformulate women's sexual subjectivity from passive to sexually active.

Käng's work similarly confirms the importance of more self-consciously "Asian” inspired and oriented sexual subjectivities. He posits a double and complex movement that both extends and in another sense effaces previous proliferations of gender categories. Kathoey, as Jackson (2003) demonstrates, became a categorical home for "trans" in a historical situation in which there were official moves to enshrine and police the visibility of gender differences between women and men under the Western colonial gaze. In that prior 
iteration, kathoey emerged as part of what was then a newly fashioned tradition of gender intermediacy. Käng argues that contemporaneously, males who identify as kathoey are now self-consciously adopting a discourse of gay modernity associated with cosmopolitan fashion and style, though one that borrows heavily from Korean pop culture. The alignment of self and modernity both informs and is informed by a systematic process through which "kathoey" are simultaneously being written out of the latest reinvention of Thai tradition, including what counts and qualifies as Thai "traditional" gender categories, and increasingly identified with the moral degeneracy of contemporary culture and increasingly medicalised notions of gender dysphoria.

Adnan Hossain's contribution revisits the now emblematic figure of South Asian gender non-conformity, the hijra, drawing on ethnographic research outside India among hijra in Bangladesh. Previous scholarship on the hijra suggests that emasculation was the essential bodily marker of hijra authenticity (Reddy, 2005). Hossain's ground-breaking study discloses that being or becoming hijra in Bangladesh does not necessarily entail either complete bodily transformation or even complete social disavowal of one's masculinity. Some Bangladeshi hijra simultaneously live as house-holding masculine-identified men and as feminine-identified hijra.

Hossain also addresses anew the question of whether or not, and to what extent, hijra gender non-conformity articulates a vernacular religious pluralism. For hijra in Bangladesh, Hossain contends, Islamic belief and practice are central to the way that they talk about themselves and normatively shape and constrain their various gender identifications, their social interactions and their erotic practices. Hijra are active interpreters of Islamic knowledge who challenge the truth claims of others seeking authority over them. At the same time, hijra in Bangladesh self-consciously draw on symbols, mythic themes and elements of ritual practice that are Hindu. Undertaking what are otherwise perceived as 
"Hindu" rituals and identifying with Hindu mythological figures, however, does not threaten their Islamic identification. Nor does it make one a Hindu, but rather a hijra, where hijrahood is understood to be not an identity that belongs to any single religious tradition, but rather an occupation defined by both literal and figurative border-crossing practices.

Key to these studies is the relevance of culturally located and produced sexual and gender identities understood as the product of state, religious, colonial and post-colonial discourses and hegemonic meanings of selves and subjectivity, of womanhood and manhood. These meanings, products of historical processes during the twentieth century, are always entangled in and part of the particular forms of gender and sexual transgression that are imagined and possible. So the Thai kathoey male is acceptable for a flamboyant performance of femininity in Thailand, which signals sexual availability to normatively gendered men. The kathoey's failure to disrupt normative sexuality helps to account for the relative tolerance of this subject position in contemporary Thailand. In contrast, the tom becomes an acceptable partner for a woman because neither is considered to be sexual in a sex/gender system that privileges men's sexuality as active.

At the same time, the anthropological lens allows a view of transnational Asian flows of meanings and styles across the region. Korean pop culture and Arabic reformist Islam, for instance, circulate across the region to become significant cultural elements of a refigured gender and sexuality. Asian subjects increasingly look to the technologically sophisticated and queer others of the region to create new meanings and proliferate new genders. While Western male sex tourists and rights based identity movements continue to mark nonWestern people and bodies as exotic and backward (see Mepschen, Duyvendak and Tonkens, 2010), the articles in this special issue suggest that for many people across this region Western gayness is no longer avant garde, no longer the symbol of ultra-modernity. Rather, the "West" (however designated and construed) is relegated to the status of a sounding board 
against which Asian subjects define themselves (see also Alexeyeff and Besnier, forthcoming).

\section{Heteronormativity, Shifting Moral Economies and Border Crossings}

Recent work that has focused on the most visibly "queer" - i.e. nominally and identifiably "trans" or "homosexual" - subjectivities reflects a more general problem for scholars who are working with and investigating queer Asian subjectivities (Gopinath, 2005). In addition to the question of who might be considered "queer", if indeed that label is useful, the overriding emphasis on the visibly queer means that we have a growing body of literature on male-tofemale (MTF) and female-to-male (FTM) forms of transgender and, to a lesser extent, on intersecting or emergent forms of distinctly same-gender sexualities - that is, women with women and men with men.

Comparatively few studies exist of the practices of people who occupy normative gender and sexual identity categories but whose erotic desires and sexual attachments and sentiments misalign with their putative location in normative heterosexuality. Examples include feminine-identified, presumed heterosexual women whose partners are both “ordinary" men and masculine-identified tombois, and masculine identified, presumed heterosexual men whose partners regularly include both women and "ordinary" men (see, for

example, Blackwood, 2010; Boyce, 2006; Lai, 2007; Sinnott, 2004; cf. Welker, 2006). ${ }^{2}$ This lack of attention to normative categories is perhaps unsurprising given the persistent way that heteronormativity is, in scholarship as in everyday life, presumed to have the stability and coherence that is publicly or officially claimed for it. As a contribution to that broader project of interrogating and queering heteronormativity, several of the papers in this special issue explore the boundaries and borders of heterosexuality, investigating both people who 
are in some way positioned as publicly transgressive and those who occupy what are perceived to be normative gender/sexual categories.

Saskia Wieringa's essay draws on research in Indonesia and India to think comparatively about the ways in which differently articulated systems of heteronormativity structure and constrain the loves and lives of three groups of women - widows, sex workers and lesbians. These women are routinely positioned outside or along the borders of conventional heterosexual sexual and social formations. Her argument creatively extends and revisits classic themes in feminist theorising. Starting from the relative durability of heterosexual privilege and the patriarchal dividend across cultures, which create an unequal distribution of economic resources, she deploys a compelling notion of "passionate aesthetics" to understand the complex regulation of erotic desires and sexuality that binds women in relations of gender and sexual inequality.

Just as importantly, Wieringa demonstrates that systems of heteronormativity do not in any simple way produce the kinds of compliant (female) bodies perfectly adapted to the system that theorists such as Bourdieu (2002) might be read as suggesting. Rather, as she notes, the body is as likely to be a source of transgressive pleasure and disaffection. Moreover, Wieringa's work discloses the multiple strategies of resistance and discrepant readings of texts that create, and are made possible by, different cultures. In that respect, she picks up on Hossain's insistence that religious sensibilities are neither fixed nor simply constraining but rather may sometimes provide both the impetus and creative resources for discrepant lives that challenge normative categorical assumptions.

While Wieringa's essay provides a provocative and, at present, rarely attempted exercise in comparative investigation across sexualities in South and Southeast Asia, Filippo Osella's essay explores the social processes and embodied effects of movement on people's affective relations and sexual subjectivities. Osella's essay investigates, in particular, the 
intersections between changes in moral economies and the shifting forms and formulations of male homosocialities of Keralite Muslim, predominantly male, migrants to the countries of the Gulf. Previously, conventional arrangements of apprenticeship and erotic partnerships bound younger men to older men and defined and produced the masculine attachments and pursuits of previous generations of male merchant traders. Those sets of affective relations were not secretive relations separated from their heterosexual masculine identifications as householding men, but rather occupied a different though no less public space in the bazaar. A subsequent decline in the bazaar economy in Southern India and the rise of outward migration has created new middle-class consumer lifestyles and the rise of a more rigid set of religious moralities that has increasingly privatised and heterosexualised affective and erotic relations and forced one aspect of male socialities to become subrosa. Thus, according to Osella, while forms of male sociality are no less intense, same-sex intimacies are increasingly confined to private parties involving secret liaisons with paid call boys.

Any project to queer Asian sexualities must consistently work against Western Orientalist assumptions about supposedly duty-bound, "family-values" Asian subjects in need of liberation from family to properly express a "free" modern sexuality. Certainly, gay liberation discourse contains an expectation of movement away from "traditional" family obligations and toward homosexual "nuclear" couples who can live openly together, an expectation now decried as "homonormative" by its critics (see, for example, Duggan, 2003; Stryker, 2008). Proper gay and lesbian subjects, in this liberationist story, should declare their independence from family expectations and refuse to marry or have children in the conventional manner. By blurring the lines between heterosexuality and homosexuality, as these essays do, a more nuanced understanding of erotic desire and multiple sexual practices emerges that exceeds simple binaries of normative heterosexuality and non-normative homosexuality. 
The circumstances of South Indian Muslim "family" men suggest that sexual encounters with young men, which were formerly a prerogative of normatively gendered men, have, with shifting economic fortunes, become less openly acknowledged but still desirable. In this context "heterosexuality" has no distinguishable meaning; there is only the privileged sexuality of adult men. The homosociality of men becomes the context in which sex with young men is possible. At the same time, as Wieringa demonstrates, the pervasive structures of heteronormativity mean that for many women, their lives are only valued and intelligible within the domains of family and motherhood. Women who find themselves excluded from these domains nevertheless adhere to heteronormative standards - for instance, of femininity or motherhood - even as they subvert those standards by creating new forms of intimacy and family.

\section{Conclusion}

The articles in this special issue provoke conversations between various iterations of sexual subjectivity across real and imagined boundaries and borders. They reveal the processes that create and undo "tradition", the movement of sexual meanings into and out of normative categories, and the negotiation of widely divergent discourses and practices to create sexual subjectivities. In so doing, these articles resist facile associations of "tradition" with genderdefined sexualities, as is typical of both Western and Asian discourses, while at the same time challenging the dominant Western assumption that sexual orientation trumps gender. Whether it is Bangladeshi hijra or Muslim Indian men seeking entertainment with male youth, all of whom express a masculine and heterosexual subjectivity in some or most contexts, erotic contact between same-sex bodies does not necessarily define their sexuality.

These apparent slippages suggest that genitalia may be irrelevant to sexual identities. Or pushing it further still, we could question the relevance of sexual identity categories to 
sexuality. For the partners, commercial or otherwise, of Bangladeshi hijra, Thai kathoey or toms, performance of appropriate gender, or maintaining a normatively gendered relationship, resolves the tensions of non-normative sexuality, allowing the culturally imagined bodies to hold sway, and making the sexed bodies irrelevant. Then again, for Thai dees, their caring toms may be more appealing in the way they differ from normative constructions of masculinity. But in this case again the relation (of opposition) to normative gender may also create the appeal.

Just as queering Asian sexualities blurs apparently stable gender and sexual categories, it also exposes the shifts in normative expectations and the way in which changing conditions rework normative meanings into new alignments. Shifting political, economic and religious conditions and discourses may upend older meanings at the same time that they produce new normative and non-normative sexualities. What Osella refers to as the ongoing process of "heteronormalisation" identifies a refashioning of normative categories of family and conjugal life in the context of changing economics and new forms of religious morality. Global flows of Islamic reformism and Indian economic liberalisation create a new form of masculine subject who must be more attentive to his sons and confine his time more to his own household. This normative refashioning produces a more narrowly defined men's sexuality in which only certain marked, effeminate youth are available for pleasure, while control of wives becomes evidence of the husband's masculinity.

Changes in gender and sexual identities documented in the Thai and South Indian cases might suggest that sexuality is a free-play zone where new styles or expectations are quickly taken up. However, heteronormative regimes in Asia continue to produce and police categories of legitimate sexuality that, for women in particular, are restricted to the conjugal embrace of one husband. For men, an active and extensive sexuality, whether with plural wives, prostitutes or young male sex workers or male companions, is constructed as the 
norm. A comparison between men's and women's conventional homosocial spaces is instructive here. As noted by Wieringa, homosocial spaces where non-sexual friendships flourish for women are oriented to family and kin; "queer" sexualities must be carefully excavated in these contexts (see Gopinath, 2005). For Muslim men in Kerala, men's spaces outside the home may more readily accommodate erotic intimacies. However, for marginalised women, as for the Kerala men in Osella's article, the everyday experiences of sexual actors may provide a critical platform from which to challenge and subvert normative expectations.

The alignment of sexuality with particular gendered bodies under heteronormativity suggests that open resistance is the only strategy for change. But as these papers have demonstrated, sexual categories are not seamless; nor are the political, economic and religious processes that produce them without alternative possibilities for sexual subjects. Queer sexualities reconfigure normative categories even as they borrow from and challenge those categories, creating multiple possibilities for change that are neither fixed nor limitless. The question that remains, however, is how long the power of normality prevails at the point where bodies touch. Can queerly defined sexualities challenge normative constructions of sexuality and gender such that sexual subjects may redefine themselves within the course of their relationships? These articles demonstrate generational shifts in normative and queer categories of sexuality, but what of individuals in long-term relationships, the lesbian with a transman, the heterosexual femme with a tomboi? How fluid is sexuality? Is it possible that in the frictions produced through the daily processes of living and enacting contested subject positions, or what Anzaldúa (1987) calls incompatible frames of reference, sexual subjects may be moved toward other ways of perceiving their relationships? In Some Like it Hot, the Hollywood movie of 1959, the apparently heterosexual Osgood Fielding III proposes to a woman played by a cross-dressed Jack 
Lemmon. Osgood's response, on finding out that his new fiancée is a man, may say it all:

"Well, nobody's perfect".

\section{Acknowledgments}

All but one of the papers in this special issue of Asian Studies Review were originally presented at the Association of Asian Studies annual meeting in Philadelphia in March 2010. We are grateful to Peter Jackson for inviting us to submit a selection of papers to Asian Studies Review and to all the other participants on our panels, Tom Boellstorff, Jane Ferguson, Rachel Harrison and Ward Keeler. Niko Besnier provided insightful comments on this introductory essay from a comparative "Pacific" vantage point.

\section{References}

Alexeyeff, Kalissa and Niko Besnier (forthcoming) Gender on the edge: Identities, politics, transformations, in Niko Besnier and Kalissa Alexeyeff (eds), Gender on the edge: Transgender, gay, and other Pacific Islanders, pp. 1-22 (Honolulu: University of Hawaii Press).

Anzaldúa, Gloria (1987) Borderlands/La Frontera: The new mestiza (San Francisco: Aunt Lute Books).

Babayan, Kathryn and Afasaneh Najmabadi, eds. (2008) Islamicate sexualities: Translations across temporal geographies of desire (Cambridge: Harvard University Press).

Bhaskaran, Suparna (2004) Made in India: Decolonization, queer sexualities, trans/national projects (New York: Palgrave Macmillan). 
Blackwood, Evelyn (2005) Gender transgression in colonial and post-colonial Indonesia. Journal of Asian Studies 64(4), pp. 849-79.

_ (2010) Falling into the lesbi world: Desire and difference in Indonesia (Honolulu: University of Hawaii Press).

Boellstorff, Tom (2005) The gay archipelago (Princeton: Princeton University Press).

_ (2007) A coincidence of desires: Anthropology, queer studies, Indonesia (Durham: Duke University Press).

_ (2011) But do not identify as gay: A proleptic genealogy of the MSM category. Cultural Anthropology 26(2), pp. 287-312.

Bose, Brinda and Subhabrata Bhattacharyya, eds. (2007) The phobic and the erotic: The politics of sexuality in contemporary India (London: Seagull Books).

Bourdieu, Pierre (2002) Masculine domination, trans. Richard Nice (Palo Alto: Stanford University Press).

Boyce, Paul (2006) Moral ambivalence and irregular practices: Contextualizing male-to-male sexualities in Calcutta/India. Feminist Review 83, pp. 79-98.

Duggan, Lisa (2003) The twilight of equality?: Neoliberalism, cultural politics, and the attack on democracy (Boston: Beacon Press).

Gopinath, Gayatri (2005) Impossible desires: Queer diasporas and South Asian public cultures (Durham, NC: Duke University Press). 
Gupta, Charu (2001) Sexuality, obscenity, community: Women, Muslims, and the Hindu public in colonial India (Delhi: Permanent Black).

Jackson, Peter and Nerida Cook, eds. (1999) Genders and sexualities in modern Thailand (Chiang Mai: Silkworm Books).

Jackson, Peter (2000) An explosion of Thai identities: Global queering and re-imagining queer theory. Culture, Health \& Sexuality 2(4), pp. 405-24.

(2003) Performative genders, perverse desires: A bio-history of Thailand's same-sex and transgender cultures. Intersections: Gender, History and Culture in the Asian Context 9. Available at http://intersections.anu.edu.au/issue9/jackson.html, accessed 28 August 2012.

—_ ed. (2011) Queer Bangkok: 21st century markets, media, and rights (Hong Kong: Hong Kong University Press).

Johnson, Mark (1997) Beauty and power: Transgendering and cultural transformation in the Southern Philippines (Oxford: Berg).

Johnson, Mark, Peter Jackson and Gilbert Herdt (2000) Critical regionalities and the study of gender and diversity in south east and east Asia. Culture, Health and Sexuality (2)4, pp. 36175.

John, Mary E. and Janaki Nair, eds. (1998) A question of silence? The sexual economies of modern India (New Delhi: Kali for Women).

Lai, Franco (2007) Lesbian masculinities: Identity and body construction among tomboys in Hong Kong, in Saskia Wieringa, Evelyn Blackwood and Abha Bhaiya (eds), Women's 
sexualities and masculinities in a globalizing Asia, pp. 159-80 (New York: Palgrave Macmillan).

Loos, Tamara (2009) Transnational histories of sexualities in Asia. American Historical Review. December, pp. 1309-24.

Manalansan, Martin (2003) Global divas: Filipino gay men in the diaspora (Durham, NC:

Duke University Press).

Manderson, Lenore and Margaret Jolly, eds. (1997) Sites of desire/economies of pleasure: Sexualities in Asia and the Pacific (Chicago: University of Chicago Press).

Martin, Fran, Peter Jackson, Mark McLelland and Audrey Yue, eds. (2008) AsiaPacifiQueer: Rethinking genders and sexualities (Urbana: University of Illinois Press).

Mepschen, Paul, Jan Duyvendak and Evelien Tonkens (2010) Sexual Politics, Orientalism and Multicultural Citizenship in the Netherlands. Sociology 44(5), pp. 962-79.

Nanda, Serena (1999) The hijras of India: Neither man nor woman (Belmont, CA: Wadsworth)

Osella, Caroline and Filippo Osella (2006) Men and masculinities in South India (London: Anthem Press).

Peletz, Michael (2007) Gender, sexuality, and body politics in modern Asia (Ann Arbor, MI: Association for Asian Studies). 
_ (2009) Gender pluralism: Southeast Asia since early modern Times (New York:

Routledge).

Rahman, Momin (2010) Queer as intersectionality: Theorizing gay Muslim identities.

Sociology 44(5), pp. 944-61.

Reddy, Gayatri (2005) With respect to sex: Negotiating hijra identity in South India (Chicago: University of Chicago Press).

Sinnott, Megan (2004) Toms and dees: Transgender identity and female same-sex relationships in Thailand (Honolulu: University of Hawaii Press).

_ (2010) Borders, diaspora and regional connections: Trends in Asian "queer" studies. Journal of Asian Studies 69(1), pp. 17-31.

Srivastava, Sanjay (2007) Passionate modernity, sexuality, consumption, and class in India (New Delhi: Routledge).

Stryker, Susan (2008) Transgender history, homonormativity, and disciplinarity. Radical History Review 100, pp. 145-57.

Vanita, Ruth, ed. (2002) Queering India: Same-sex love and eroticism in Indian culture and society (New York: Routledge).

Vanita, Ruth and Saleem Kidwai, eds. (2000) Same-sex love in India: Readings from literature and history (New York: Palgrave). 
Wekker, Gloria (2006) The politics of passion: Women's sexual culture in the Afro-

Surinamese diaspora (New York: Columbia University Press).

Welker, James and Lucetta Kam (2006) Introduction: Of queer import(s): Sexualities, genders and rights in Asia. Intersections: Gender, History and Culture in the Asian Context 14. Available at http://intersections.anu.edu.au/issue14/introduction.htm, accessed 28 August 2012.

Wieringa, Saskia E., Evelyn Blackwood and Abha Bhaiya, eds. (2007) Women's sexualities and masculinities in a globalizing Asia (New York: Palgrave MacMillan).

Wilson, Ara (2004) The intimate economies of Bangkok: Tomboys, tycoons, and Avon ladies in the global city (Berkeley and Los Angeles: University of California Press).

— (2006) Queering Asia. Intersections: Gender, History and Culture in the Asian Context 14. Available at http://intersections.anu.edu.au/issue14/wilson.html, accessed 28 August 2012.

\footnotetext{
${ }^{1}$ A complete review of the recent literature on queer subjectivities and more broadly on gender and sexual diversity within, across and beyond South and Southeast Asia, respectively, is outside the remit of this introductory piece; some of that literature is the subject of more systematic analysis in the review pieces cited in the text (see also Loos, 2009). In this essay we only directly refer to those works that have a particular bearing on the points under discussion. However, we are indebted to that wider body of scholarship on which we seek to build here. Readers unfamiliar with that scholarship may wish to consult some of the following major monographs and edited collections published in the last fifteen years, e.g. Babayan and Najmabadi (2008), Blackwood (2005; 2010), Boellstorff (2005; 2007), Bose and Bhattacharyya (2007), Bhaskaran (2004), Gopinath (2005), Gupta (2001), Jackson (2011), Jackson and Cook (1999), Johnson (1997), Johnson, Jackson and Herdt
} 
(2000), John and Nair (1998), Manalansan (2003), Manderson and Jolly (1997), Martin, Jackson, McClelland and Yue (2008), Nanda (1999), Osella and Osella (2006), Peletz (2007; 2009), Reddy (2005), Sinnott (2004), Srivastava (2007), Vanita (2002), Vanita and Kidwai (2000), Welker and Kam (2006), Wieringa, Blackwood and Bhaiya (2007) and Wilson (2004; 2006).

${ }^{2}$ There is a substantial body of work on MSM (men who have sex with men) although much of it focuses on health-related issues. For a critical reading of the emergence of this putative "non-identity" category, see Boellstorff (2011). 